Chapter 5

\title{
Managing Green Innovations in the Building sector
}

In the previous chapters of this book, the attention was focussed on sustainable buildings in order to clarify the concept of sustainable building and the goal of the management of green innovations in the building sector. The latter is central in the second part of the book.

This chapter starts with a brief introduction to innovation management. Ways to classify innovations are reported by considering the impact of innovations over firms. The distinction between modular and radical innovations is reported before focussing on architectural innovations (Henderson \& Clark, 1990). A review of studies about architectural innovations is done, as these innovations can play a prime role for a sustainability transition but, at the same time, they are particularly complicated to manage. In particular, the interest in focussing on architectural innovations is given by their complexity for the production processes.

In the second part of the chapter, the discussion concentrates on innovations in the building sector, often considered low on the scale of innovation. However, several researchers have recently given a new attention to peculiarities of construction innovations. Studies have demonstrated that innovations in buildings are often user-generated, on-site developed, numerous and undeclared. The chapter describes the introduction and diffusion of incremental and radical innovations in the building sector, and it ends discussing the effects of architectural and green innovations when they are adopted in buildings.

\subsection{Classifications of Innovation}

Innovation is a widely used, but elusive concept. Definitions of this term rarely went beyond the common understanding of innovation as "something new" (Schumpeter, 1976). Innovation literature has often discussed three themes: classification of innovation (1), innovation drivers (2), and response to innovation (3).

Firstly, a main theme of research has been the classification of the forms of innovation (Henderson \& Clark, 1990). In particular, within the innovation management literature, an innovation can be either a continuous process or a discontinuous and radical phenomenon. How the innovation is generated is still an open question. 
A secondary theme of research has often concerned with the place where innovation occurs. In particular, it has often been of interest if an innovation occurs within closed systems or is boundless. Researchers have found innovation almost everywhere: in creative or entrepreneurial individuals (Schumpeter, 1976), complex multilevel groups (Watson, 2007), knowledge clusters (Pohoryles, 2007), networks and governance structures (Johns et al., 2006). These contrasting results show the importance of the topic.

A third interesting theme for innovation management literature regards the behaviours and the responses to innovation at the individual, group, and contextual levels. Personal factors include the openness to new ideas (Ross, 1974) and tacit knowledge (Howells, 2002). It also considers how peoples' roles, positions, and self-definitions affect their responses (Considine 8 Lewis, 2007), their freedom to take risks (Lassen et al., 2006), and how the presence of a leadership role fosters innovation (Benn et al., 2006).

For a long time, innovation was seen as a synonym of invention. However, while invention refers to a new aspect of production, innovation is mostly related to the application of research results (Schumpeter, 1976). Innovation is the process of creative destruction which essentially revolutionises the economic structure from within, and constitutes the essential of transformative capitalism (Schumpeter, 1976). Innovation is hence the creative implementation of the new that takes place against a resistant background of everyday activity.

Literature has often tried to classify innovations according to their impact over firm capabilities. Innovations have been divided into two categories: competence-enhancing and competence-destroying. Moreover, innovations have been classified for their connections between product and process innovations. Especially in recent years, innovations have enlarged their boundaries passing from mainly product-related aspects to concepts of practices, processes and structures (Birkinshaw et al., 2008). Furthermore, in recent years, process and service innovations have received a larger attention than traditional product innovations (Pisano, 1996).

Pisano (1996) defined four perspectives in innovation studies: an institutional perspective that focusses on the socioeconomic conditions, a fashion perspective that focusses on the dynamic interplay between users, a cultural perspective that focusses on how an organisation reacts to the introduction of an innovation, and a rational perspective that focusses on how innovation management and individuals deliver improvements in organisational effectiveness.

Patents and R\&D expenditures are the most-used parameters in innovation studies. These best apply to product innovations. However, processes and organisational innovations are more difficult to understand and measure (Nelson $\&$ Winter, 1982). Recent studies about innovations are considering more social 
than economic aspects of innovations. In fact, innovation impacts, degrees of effort, development path timings and technological momentum are increasingly studied (Dosi, 2000).

Innovations have been divided into incremental and radical if minor or major changes are imposed by their adoption, respectively (Mansfield, 1968). Later, Freeman (1982) differentiated incremental from radical innovations as improvements in existing concepts from introducing new designs. An incremental innovation introduces relatively minor changes to the existing products, exploits the potential of the established design, and generally reinforces the dominance of established firms (Nelson \& Winter, 1982). On the contrary, a radical innovation bases on a different set of scientific principles and, generally, opens up completely new applications (Dutton \& Jackson, 1987; Ettlie, 1997).

Limits of the simple incremental vs. radical classification were shown during the 1980s when innovations involving modest changes provoked dramatic competitive consequences (Clark, 1987). Henderson and Clark (1990) proposed a new classification of innovation analysing the linkages between core concepts of a product and its components. They defined four types of innovations, which can be distinguished if the core concepts are reinforced and if the linkages between concepts and components are changed by the innovation. They indicated four categories of innovation, as reported in Table 5.1.

Henderson and Clark's categories can be described in the following way:

- Incremental innovation introduces relatively minor changes to the existing products and processes;

- Modular innovation substitutes a modular element with a new one which generally guarantees a better performance, but which does not need new linkages with other components and maintains the same connections of the overturned element;

- Architectural innovation is a change of a product architecture which leaves unchanged the components and the core design concepts, but elements are reconfigured with new iterations;

- Radical innovation is based on a different set of principles, and often opens up whole new markets and potential applications.

Table 5.1 Classifications of innovation according to Henderson and Clark (1990).

\begin{tabular}{|l|l|l|l|}
\hline & & \multicolumn{2}{|c|}{ Core Concepts } \\
\hline & & Reinforced & Overturned \\
\hline $\begin{array}{l}\text { Linkage Between } \\
\text { Core Concept and } \\
\text { Components }\end{array}$ & Unchanged & Incremental Innovation & Modular Innovation \\
\cline { 2 - 4 } & Changed & Architectural Innovation & Radical Innovation \\
\hline
\end{tabular}


Slaughter (1998) added the category of system innovation. She defined the system innovation as being composed of a large number of innovations. Although the previous categories exist, many innovations are difficult to classify for the difficulties of defining the core concepts and linkages between core concept and components. Moreover, innovation diffusion often leads to an evolutionary pattern which locally modifies the innovation at any introduction (Cainarca et al., 1989). The possibility of evolution trends for innovations suggests considering innovation as a dynamic paradigm (Birkinshaw et al., 2008). The dynamics of impacts and site adaptations of innovation will be considered in the following sections.

\subsection{Specificities of Architectural Innovations}

The present section is dedicated to architectural innovations. The reason behind the interest in architectural innovations will become clearer in Chapter 7 , investigating the impact over the building process of green innovations which are architectural innovations. However, it is possible to say that innovations which need to be integrated in an existing object and which have a strong impact for the architecture of that object (so that they are architectural innovations) represent a significant body of the innovations that the building sector should learn to implement for more sustainable buildings.

Architectural innovations have significant effects over complex products, such as buildings. These usually consist of a large number of components. The architecture concept of a product encompasses the information on how many components the product consists of, how these components are configured together, and how they are built and assembled. The architecture defines the building blocks in terms of what they do and what their interfaces are (Ulrich \& Eppinger, 2000). Table 5.2 reports some definitions of architecture in the context of innovation management.

The concept of architecture is related to that of function both represent what a product does (Ulrich, 1995). In studies about architectures, the interfaces among components play a principal role. Many studies have explored modular architectures because these are the simplest configuration for a product, and they have a one-to-one mapping between functional elements and components. Modular architectures were studied by Baldwin and Clark (2000) who indicated three kinds of modularity: in design, in production, and in use. The concept of architecture has extensively been investigated by the Architecture Committee in the Engineering System Department of the Massachusetts Institute of Technology. These studies have focussed on the abstraction of the systems and on the role and influence of architecture in complex systems (Crawley et al., 2004). Ulrich (1995) stated that architecture is relevant for innovation management, as architectural decisions are made in the early phases of the innovation process. The 
Table 5.2 Definitions of architecture, according to different sources.

\begin{tabular}{|c|c|}
\hline Source & Definition of the Architecture (of a product) \\
\hline Ulrich and Seering, 1990 & $\begin{array}{l}\text { knowledge about the functions of the system and how the } \\
\text { components contribute to those functions, which means what } \\
\text { they do }\end{array}$ \\
\hline Ulrich, 1995 & $\begin{array}{l}\text { the scheme by which the functions of a product are allocated to } \\
\text { physical components }\end{array}$ \\
\hline Ulrich and Eppinger, 2000 & the arrangement of the functional elements into physical blocks \\
\hline Baldwin and Clark, 2000 & the modules that are part of the system, and what their roles are \\
\hline Crawley et al., 2004 & $\begin{array}{l}\text { an abstract description of the entities of a system and the } \\
\text { relationship between those entities }\end{array}$ \\
\hline Crawley et al., 2004 & $\begin{array}{l}\text { the embodiment of concept, and the allocation of physical/ } \\
\text { informational function to elements of form, and definition of } \\
\text { interfaces among the elements and the surrounding context }\end{array}$ \\
\hline Fixson, 2005 & $\begin{array}{l}\text { the fundamental structure of the product, a comprehensive } \\
\text { description of a bundle of product characteristics, including } \\
\text { number and type of components, number and type of interfaces } \\
\text { between those components }\end{array}$ \\
\hline
\end{tabular}

importance of the characteristics of innovation in order to implement them in the building sector is particularly high.

Baldwin and Clark (2000) treated the architecture as the abstract description of the entities of a system together with their relationships. In this sense, every system has an architectural structure (Crawley et al., 2004). Obviously, the building represents the best example of product architecture.

Levis (1999) indicated several types of architectures:

- functional architecture, as the ordered list of activities and functions;

- physical architecture, as the representation of resources and interconnections;

- technical architecture, as the elaboration of physical architecture, and the interdependence of the elements;

- operational architecture, as the description of how elements operate and interact.

Architectural knowledge has been defined as the pattern of how components are arranged (Peine, 2009). Obviously, the more complex a product is, the more the architecture is important and the interoperability between components determines far-reaching implications for innovation management. 
According to the original concept, an architectural innovation leaves the components and the core concept unchanged. The essence of an architectural innovation is hence the reconfiguration of established systems to link together components in a new way. Since the core concepts of the design remain untouched in architectural innovation, organisations in front of an architectural innovation may mistakenly believe to understand the innovation. On the contrary, recognising that a new technology is architectural in character prompts to switch to a new learning process by investing time and resources. Architectural knowledge is a relevant factor for the capacity to innovate. In fact, when organisations facing innovations continue to rely on their old architectural knowledge, they generally misunderstand the nature of the innovation. Innovation classifications in Section 5.1 can also be considered according to the impact provoked by their adoption: architectural innovations often are silent innovations, although they can be disruptive for consolidated knowledge (Henderson \& Clark, 1990; Geroski, 2000). The impact and the barriers to implement and manage an architectural innovation will be the topic of the next section.

\subsection{Architectural Innovation Management}

The process of innovation management has been defined by Abernathy and Utterback (1978) as the life-cycle from an early moment dominated by intensive competition among different possibilities, through a transitional moment in which a dominant design emerges and it is improved. In its broadest sense, innovation management can be defined as the form and quality of organisational activities (Poole \& Van de Ven, 2004). Links between innovation management and inventions have often suggested co-evolution patterns between these. However, a great distance exists between research for invention and innovation management penetrations (Fuggetta, 2009).

The management of architectural innovations is interesting to study because architectural innovation needs a deep management of the new linkages between core concept and components. The concept of architectural innovation was originally defined within a single-firm context; recently it has been applied also to inter-firm contexts (Bozdogan at al., 1998). Studies have shown that supplier integration into the company can help the introduction of architectural innovations. In fact, early supplier participation is a major source of competitive advantage to firms attempting to re-invent their products (Baldwin \& Clark, 2000). The importance of innovation networks among firms is increasingly investigated, as product technology is becoming complex. In fact, complex technologies cannot be fully understood in detail by a single firm, and impose a supply chain network among several firms with different capabilities (Kash \& Rycroft, 2003). 
The management of architectural innovation is particularly critical in the early phases (also known as pre-project activity, concept generation, product planning, idea generation or investigation) because at these stages critical decisions related to the innovations are done (Verganti, 1997). The great importance of innovation management in early phases is due to the high costs and time consumption that adjustments in later stages provoke (Figure 5.1).

An important aspect which can improve the management of architectural innovations is the active integration of suppliers during the exploration stages. This involvement can foster architectural innovations in product definition, resulting in new configurations of how components are linked together in a product. Technical skills of partners can have a key role in the team, also because suppliers are more and more a source of innovation in any sector (von Hippel, 1988). Researchers working in the U.S. defence aircraft industry have shown that suppliers are involved early in the design and development of major components in the $75 \%$ of innovation cases (Bozdogan et al., 1998). This underlines the fact that the architectural management innovation is favoured by early suppliers' involvement. Such circumstance moves innovation management from company to network of firms (Ettlie, 1996).

This review of principles of architectural innovation management shows that process and organisational innovations are as necessary as technology ones. In fact, the management of architectural innovations more than other kinds of

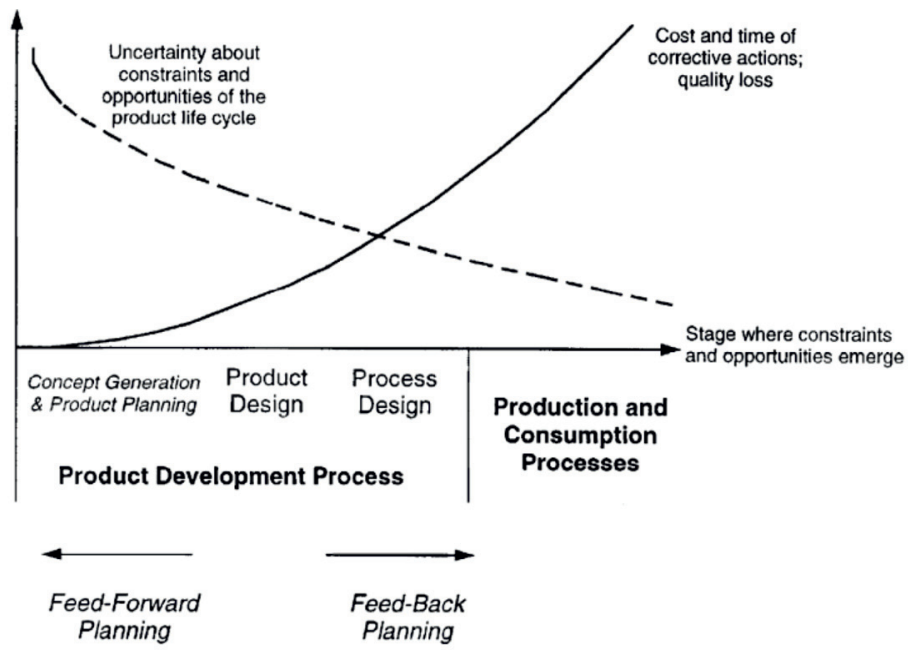

Figure 5.1 Level of uncertainty and cost/time implications during an innovation life cycle

(Verganti, 1997). 
innovations involves institutions, professional norms, practices, lifestyles, and belief systems. These elements will become clearer when the management of architectural innovation in the building sector is described.

\subsection{Innovation in the Building Sector}

\subsubsection{Construction innovation literature}

The general literature about innovation management has proved to be unable to properly fit innovations in the construction sector, because a less formally structured process characterises construction activities. Construction innovation has been an increasing subject in international research (Manseau \& Seaden, 2001).

Before reviewing this literature, it is necessary to define what the construction sector is, which is defined by its boundaries and its innovations. Construction is primarily defined as the series of on-site activities of assembly together with the activities for the production of goods that are assembled.

A negative stereotype states that construction innovation rate lags behind other sectors (Manseau \& Seaden, 2001). One of the reasons is the use of the formal investment in R\&D as a measurement unit for the innovation rate. In the construction sector, R\&D is behind the value R\&D has in other industries (Manseau \& Seaden, 2001). For example, in U.S. research on building practices and technologies constituted about $0.2 \%$ of all federal funded research from 2002 to 2004, a low percentage if compared with building-related environmental and economic impacts.

This has favoured the consideration that the construction sector is riskaverse and is conservative with respect to innovations. Almost 30 years ago, the construction sector was defined as the industry that "God forgot and the industrial revolution overlooked" (Lawrence \& Dyer, 1983).

A factor which delays innovation diffusion in constructions is the instability of construction processes and markets. Those studies, which affirmed the low innovativeness of the construction sector, generally focussed on construction companies only. Construction companies are strongly dependent on economic cycles, as they work only when construction is in progress. This cyclical situation represents a barrier to innovations for construction firms. Moreover, regulations heavily influence the layout and the scheduling of the activities at the jobsite and represent other barriers to innovations (Nam \& Tatum, 1989).

However, a conceptual mistake exists in this approach. Construction innovation studies have avoided understanding that building innovations are often "off the shelf". In fact, the analysis of only those firms that are found on 
the site presents a misleadingly simplistic view about the complexity of the construction production system, because it neglects the large number of firms that effectively participate in the building process.

Some new methods have been used to assess construction innovations in other firms of the construction sector. These methods include patent mapping, root cause analysis and TRIZ function. However, these methods and unit of measurements are unable to capture the innovation rate of the construction sector. In fact, construction related studies have underestimated the network dimension of the sector, which cannot be considered by just looking at one single firm or process.

Approaches centred on networks of firms, such as the OECD's Oslo model, have recently been proposed. New data for innovation measurements in construction have started to be based on Construction Cluster Approaches (Dahl $\&$ Dalum, 2001). From this literature, it emerges that construction is a variegated and complex sector, in which innovation emerges in different ways than in other sectors. Slaughter $(1993,1998)$ observed that the building sector depends on other industries. She also underlined the importance of ad-hoc micro innovations, which generate from fitting every project to the unique conditions of any particular application (Slaughter, 2000).

\subsubsection{Categories of construction innovations}

An innovation is a product, process or practice new to the state of the art. Most innovation studies analyse the innovations as discrete and independent events. The independence among innovations may be appropriate for manufacture innovations, where product and processes can be examined separately from other components and systems, but it is difficult to apply to the construction sector. In fact, construction processes are particularly interconnected and their innovations influence the phases with many more implications.

In Section 5.2, different kinds of innovations, spanning from radical to incremental innovations, have been described. That classification is useful for construction innovations too. Incremental innovations have often been considered the only kind of innovations in the building sector (Slaughter, 1996). Reasons for this are connected to the low innovations in design. However, Table 5.3 shows that other kinds of innovations are also possible.

In the building sector, when significant changes are necessary, they often combine many modular innovations. In these cases, innovations are not introduced in isolation but through the coordination of multiple innovations. This led Slaughter (2000) to define the system innovation. These are produced as summations of several interdependent innovations which are favoured by clusters of firms. System interactions are nurtured through coordinated innovation development programmers by firms which interact with networks 
Table 5.3 Classification of innovation in categories and their characteristics and example in the building sector.

\begin{tabular}{|c|c|c|c|}
\hline Innovation & Definition & $\begin{array}{l}\text { Characteristics } \\
\text { in the building sector }\end{array}$ & Example \\
\hline Incremental & $\begin{array}{l}\text { Small } \\
\text { improvement with } \\
\text { minimal impact } \\
\text { on other systems } \\
\text { (Nelson \& Winter, } \\
\text { 1977) }\end{array}$ & $\begin{array}{l}\text { Many rules of thumb } \\
\text { which effect unique } \\
\text { conditions or client } \\
\text { requirements often } \\
\text { adopted for cost saving, } \\
\text { convenience or new } \\
\text { regulations }\end{array}$ & \\
\hline Modular & $\begin{array}{l}\text { Improvement } \\
\text { within a specific } \\
\text { system with no } \\
\text { changes in other } \\
\text { components } \\
\text { (Winch, 1998) }\end{array}$ & $\begin{array}{l}\text { Innovations which come } \\
\text { from manufactures } \\
\text { or suppliers of new } \\
\text { products. These are } \\
\text { product innovations as } \\
\text { construction focusses on } \\
\text { product enhancement } \\
\text { more than process } \\
\text { innovations }\end{array}$ & \\
\hline Architectural & $\begin{array}{l}\text { New way of } \\
\text { assembling } \\
\text { buildings and } \\
\text { reorganising } \\
\text { practices } \\
\text { (Slaughter, 1993) }\end{array}$ & $\begin{array}{l}\text { Mobile tower cranes } \\
\text { accelerated the } \\
\text { construction process in } \\
\text { the US ('mobile crane } \\
\text { culture'). Indoor Air } \\
\text { systems are modifying } \\
\text { architectural connections } \\
\text { of building elements }\end{array}$ & \\
\hline System & $\begin{array}{l}\text { Sets of large } \\
\text { number of } \\
\text { interdependent } \\
\text { new products } \\
\text { and practices } \\
\text { (Slaughter, 1993; } \\
\text { Cainarca et al. } \\
\text { 1989) }\end{array}$ & $\begin{array}{l}\text { Computerisation has } \\
\text { involved a process of } \\
\text { integration among } \\
\text { complementarily } \\
\text { activities based on } \\
\text { innovations. The interior } \\
\text { "drywall" allows the } \\
\text { integration of many other } \\
\text { small innovations }\end{array}$ & \\
\hline Radical & $\begin{array}{l}\text { A completely new } \\
\text { concept which } \\
\text { renders overturned } \\
\text { previous } \\
\text { approaches } \\
\text { (Nelson \& Winter, } \\
\text { 1977) }\end{array}$ & $\begin{array}{l}\text { The introduction of } \\
\text { concrete disrupted } \\
\text { the sector knowledge, } \\
\text { methods and } \\
\text { technologies. Earth } \\
\text { brick can have the same } \\
\text { impacts over the sector. }\end{array}$ & 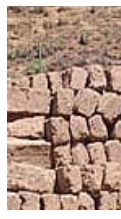 \\
\hline
\end{tabular}

of other firms (Foray \& Freeman, 1993). Table 5.3 reports the classification, characteristics and some examples of different categories of innovations in the construction sector.

A few years ago, Gann (1994) indicated four major categories of construction innovations: the use of information technology, mechanisation of construction 
activities, prefabrication, and diffusion of new materials. Mechanisation and prefabrication are two categories of innovations which have failed to be promising in past decades, whereas new materials are a continuing source of innovations, as subsequent discoveries continually permit new products.

\subsection{Actors for Innovation in Construction}

The different actors of the construction sector have different influences towards innovation. In principle, construction consists of an aggregation of clients, regulators, contractors, consultants, architects, engineers, and components suppliers, who all together form a complex system industry (Figure 5.2).

The identification of the role of actors as drivers of construction innovation has received a large attention in the last twenty years. A brief review of this literature is reported below. Winch (1998) indicates two integrators among construction stakeholders: one at the design stage (the design team), and one at the construction stage (the contractor).

The role of clients has been largely discussed. Gibb and Isack (2001) argue that public and commercial constructions are client-demanded. However, in the

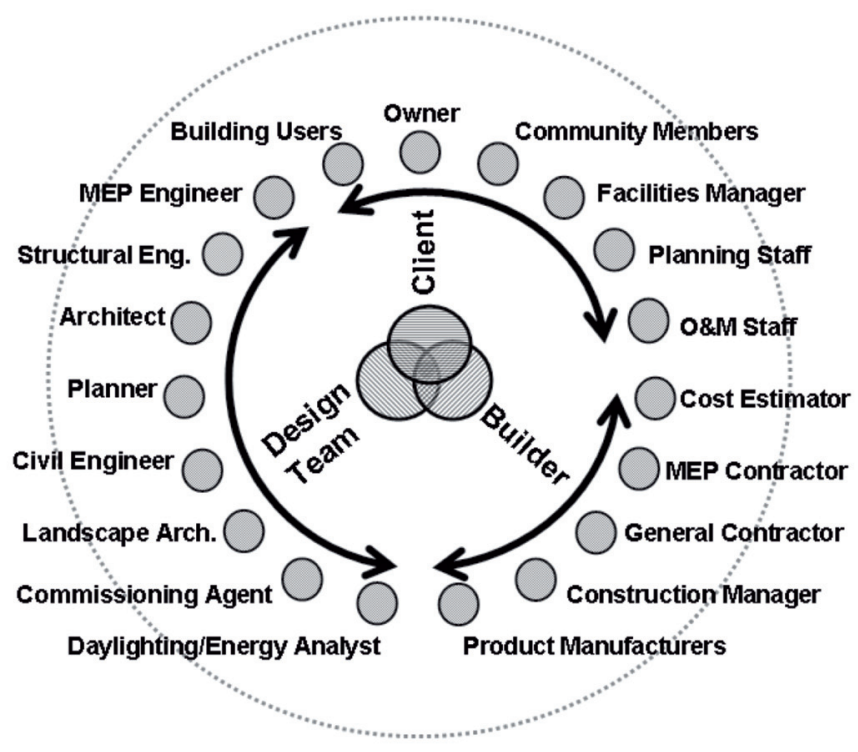

Figure 5.2 Cycles of the stakeholders of a building process grouped in three categories: design team, client and builder (Kubba, 2010). 
residential sector, according to Nam and Tatum (1992), client and users demand for innovation are largely a myth. They affirmed that the information imbalance on user opinions led clients to a lack of information to push innovation. Moreover, according to these researchers, there is a self-reinforcing consensus about what a building should look like, and how it performs. This is a reason for clients to silently accept traditional buildings.

Arditi and Kale (1997) argued that innovations are introduced by manufactures of building products. Agapiou and Flagan (1998) affirmed that markets have a prime role, whereas Bernstein and Lemer (1996) stressed the importance of customers. More recently, Sexton and Barrett (2003) have shown that owner's attitudes for innovations are key characteristics for helping the introduction of an innovation in a project. Ling (2003) stated that innovations are based on the behaviour of individuals and thus no classifications of the possible reasons for innovation is possible. Winch (1998) stressed the role of member of professional associations and regulators as drivers of innovations, because they act as integrators and knowledge brokers. Slaughter (1993) concluded that innovation arises from people and firms working on-site explicitly integrating sub-components into the total building system.

If many studies have considered construction actors as drivers of innovations, many others have looked at actors as barriers to innovation in construction. Bernstein and Lemer (1996) pointed out three categories of barriers:

- structural characteristics of the processes as a large number of small firms that interact; multitude of codes and standards, cyclical downturns;

- cultural factors, as emphasis on lowest initial cost, division between labour and craft participants, strong reliance on past experience;

- general impediments, as tort liability, threat of litigation, and high costs.

Bauman and Kracum (1995) focussed on innovation barriers as financing, government regulations, public and political pressures. Tangkar and Arditi (2000) presented the process of innovation in construction as a labyrinth among which many actors collaborate through five phases: invention, creation of innovation, recognition of a need, construction of an environment for the adoption, and diffusion of the innovation.

Governments have sometimes been seen as barriers; however they have often played a prime role as drivers for the introduction of innovations in construction. Unfortunately, regulations generally apply only to new buildings and significant renovations. In developed countries, the construction rate of new buildings compared to the renovation rate of existing buildings is small. For example, in Europe, the estimated annual replacement rate is only 0.07\% (CRESME, 2010). Data about the building industry in developing countries, reported in Chapter 1 , suggests that regulations can have sizable impacts in these countries. 
Several models have been used to understand and drive innovation diffusion in the building sector as technology-push or market-pull models. Simple models have proved to be partially useful in the building sector, given its complexities. Consequently, many non-linear models have been proposed to describe the introduction of innovations:

- firm-centred knowledge networks, theoretically based on the Oslo Manual. In these models, the firm is considered an innovation dynamo, and the distance among actors is the principal influencing factor for innovation.

- production systems that consider the implementation of new ideas after the interaction among workers, so that the relationships which characterise the production system become fundamental.

- complex product systems considers the integration between the innovations in existing systems.

- social processes that give social properties and perspectives to the innovations. These determine a continuous and evolutionary process among actors who interact collectively.

Previous models represent different drivers to understand construction innovations.

Many of the recent innovations in the construction sector are related to sustainable building. In a recent research, Mokhlesian (2010) has focussed on the adoption of innovations for green construction and has found that networks of motivated firms are dominant drivers for the adoption of green innovations. Absorptive capacity obtained though knowledge sharing between partners (Gluch et al., 2009; Bossnik, 2004), or information diffusion (Bartlett \& Howard, 2000; Tam et al., 2006) are other main drivers for innovations for sustainable buildings. Finally, it is possible to affirm that higher-order knowledge among stakeholders is required to manage the adoption of innovations in the building sector because this requires that all participants are committed and motivated towards the innovation (Ahmad, 1991).

Slaughter (1993) found that a vast majority of innovations is developed by builders, and contrarily to the common knowledge, construction firms have importance as manufacturers. Using thirty-four innovations as case studies, she underlined the difference in user against manufacture innovations. In her study, builders integrated the products into the total building system and mainly acted over the whole final product, whereas manufacturer innovations were generally confined to single products. Moreover, she found that manufactures commercialised a few of builders' innovations, avoiding those that involved connections of the products with other components because these connections were out from the 
control of manufactures. According to Slaughter's results, users of building technologies can be important drivers of innovations because the builders can accommodate innovations according to on-site requests (Slaughter, 1993).

A key element that allows for workers to act as champions of innovations is a high competence and experience. At the same time, small firms are extremely sensitive to the cyclic and seasonal nature of the construction market, and hence, they become less inclined to pursue innovations, and long with them, and higher costs.

The approach to the multi-agent relationships in construction has often focussed on the different behaviours during the several stages of construction. In fact, one of the limits to the introduction of innovations is the time in which any stakeholder participates in the construction process. Construction generally starts with the municipal planning, so governments have the first possibility to push innovation. After this, process is ruled by the general contractors, and influenced by the design teams. Lastly, the owner or the future occupants join the process, when the majority of decisions have already been made. In Chapter 6 , this timeline approach to innovation management and actors' participations will be extensively described.

\subsection{Moving to Green Innovations}

Studies dealing with organisational aspects related to the adoption of green innovations are particularly relevant for the present book. Many authors have investigated the development of green products by looking at the networks and collaborations among stakeholders both within the firm and outside it. These studies have showed that collaborations are particularly crucial for green innovations (Dermody \& Hanmer-Lloyd, 1998; Foster \& Green, 2000; Seuring, 2004).

Dermody and Hanmer-Lloyd (1998) identified three drivers for the integration of green topics in production processes:

- Environmentally skilled people are integrated in the process;

- Existing members start focussing on environmental issues;

- External consultants or designers are used to assist the decision-making unit.

Lenox and Ehrenfeld (1997) studied the organisational process for sustainable design according to resource- based views, capabilities perspectives, organisational learning and exploitation literature. The authors discussed environmental design capabilities, and found that 
these capabilities develop by the execution of problem-solving activities. Lenox and Ehrenfeld (1997) stated that environmental design capabilities depend on:

- knowledge resources, both internal and external to the firm, in term of experts on environmental impacts and technologies, and knowledge on environmental demand.

- information networks between product development members and resources.

- easily communicable structures between product development team members.

These elements require building a network in which communication linkages connect different knowledge resource nodes (Figure 5.3). The coordination of different resources with the product design team needs a dense information network both within the firm and outside it. This can be facilitated by having a common language and structures in which customers and manufactures can communicate with the design team.

An important study which focussed on green innovations and inter-firm networks has been conducted by Foster and Green (2000). These investigated how green concepts are influencing innovation development, and how information networks can contribute to green issues. The signal flows between stakeholders in an idealised company are modelled in Figure 5.4. In this model,

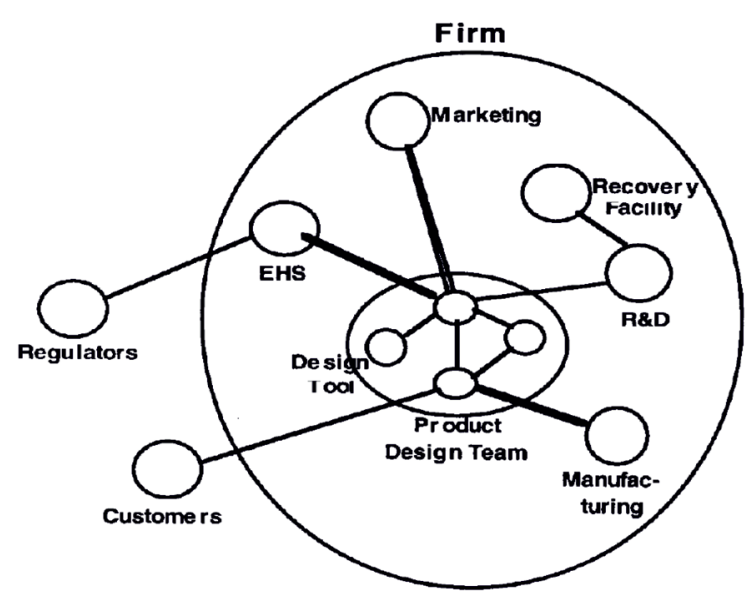

Figure 5.3 Information network of the product design team within and outside the firm (Lenox \& Ehrenfeld, 1997). 
the sale function is fundamental because it is the principal interface between users and RED function. This model is complicated by the presence of a unit dedicated to environmental management, which interfaces with both the R\&D function and regulators outside the firm. Applying this model to nine case studies, Foster and Green (2000) found that information related to green aspects encounters many obstacles to reach the R\&D stage. Moreover, the authors identified three situations which indicated different levels of importance for the green performance issues. In most cases, these can be:

- a key issue for the customer and a driving force for the innovation.

- a key issue for the R\&D and sales functions given the opportunity of new markets.

- a simple compliance check which receives little effort.

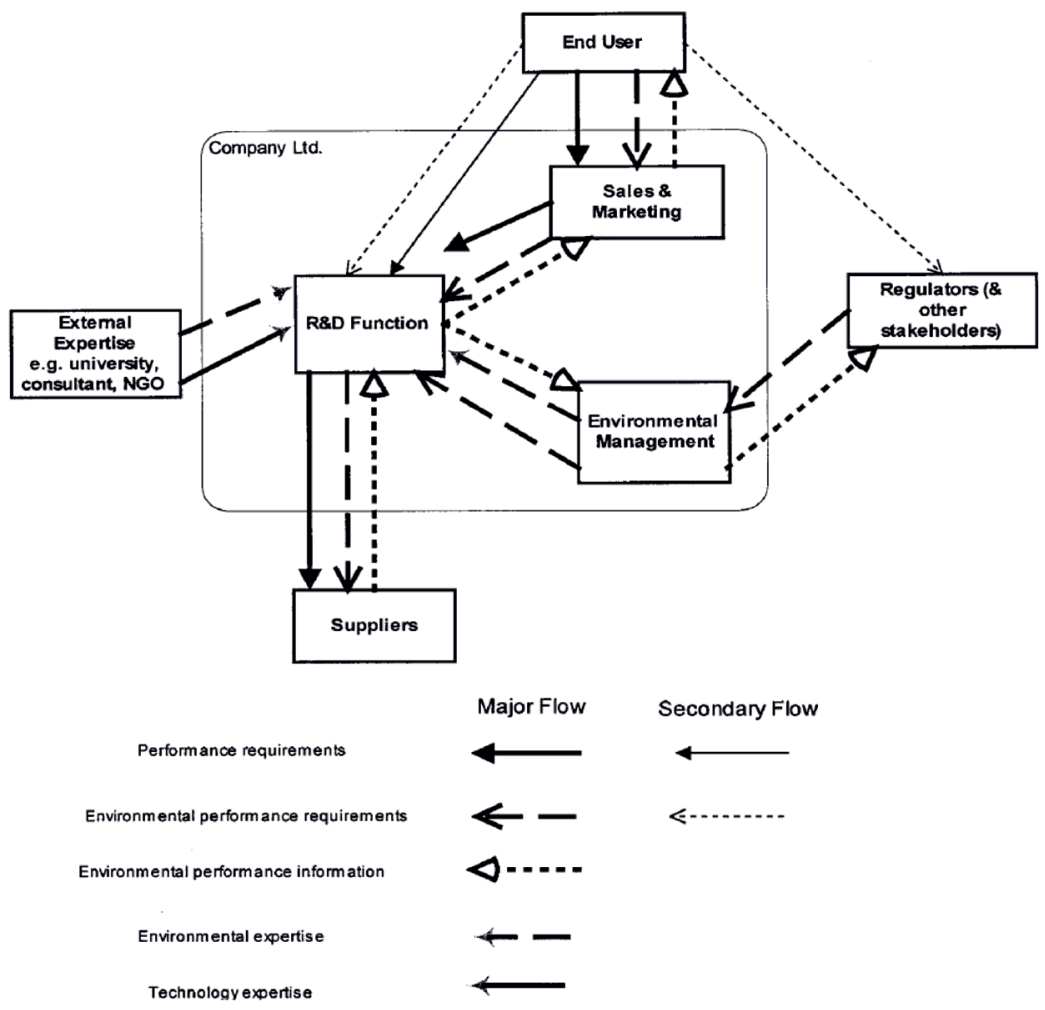

Figure 5.4 Information network in and outside a company with level of flow of each interaction according to the kind of line (Foster \& Green, 2000). 


\subsubsection{Moving the building sector towards green innovations}

Sustainable buildings require a higher-order learning which involves new practices of individuals and new institutional paradigms for the adoption of green innovations. As seen previously, a sustainable building is not the simple addition of green technologies and innovations; it requires a holistic approach. A sustainable building needs to be projected and built from an entire life cycle perspective. This means that sustainability principles have to be considered from the project planning phase through the operation and post construction phases (Wu and Pheng Low, 2010).

One way to facilitate the transition to sustainability is through experimentation (Kemp, 1996). A large amount of literature has investigated the first practices of management of sustainable innovations in different sectors (Kemp et al., 1998; Kemp et al., 2005; Bossink, 2007). These studies have shown the importance of experiments in niches to solve the problematic aspects of novelties.

A similar approach has been related to the introduction of an innovation in the construction sector as well. Here, the adoption of sustainable innovations has shown to require a multi-level learning process which involves individuals, institutions and firms (Brown \& Vergragt, 2008). An integrative model to explain the adoption of green innovations in new constructions was formulated by Vermeulen and Hovens (2006). They studied the influence on innovation adoption of economic aspects, governmental interventions, company characteristics, markets and society influences (Figure 5.5). They considered the influence of four factors to adoption of sustainable innovations in buildings: the occasion to innovate, the initial perception of the technology, the nature of the decision-making process about innovation, and the result of the assessment of the technology. This study has shown the difference between mature and young green technologies: while young innovations are generally considered as project-specific choices and can be driven by several motivations, mature innovations need all previous steps for success. Vermeulen and Hovens (2006) showed that local policies have an important role in explaining the diffusion of sustainable innovations. Moreover, subsidies and requests by partners have motivating effects.

A general assumption in theories about innovation adoption is that ideas are institutionalised through a process where individuals collectively create a meaning based on their previous knowledge and their social context (Sharma, 2000). In this process, notions are translated into actions. The interpretation and translation of the sustainability requests depends on contextual organisational factors and how corporations legitimized sustainable innovations (Sharma, 2000). As an implication, individuals interpret and act according to their power and interest. In fact, actors commonly determine their preference based on selfinterest (Gluch, 2005). They also use their own behaviour as a standard of what 


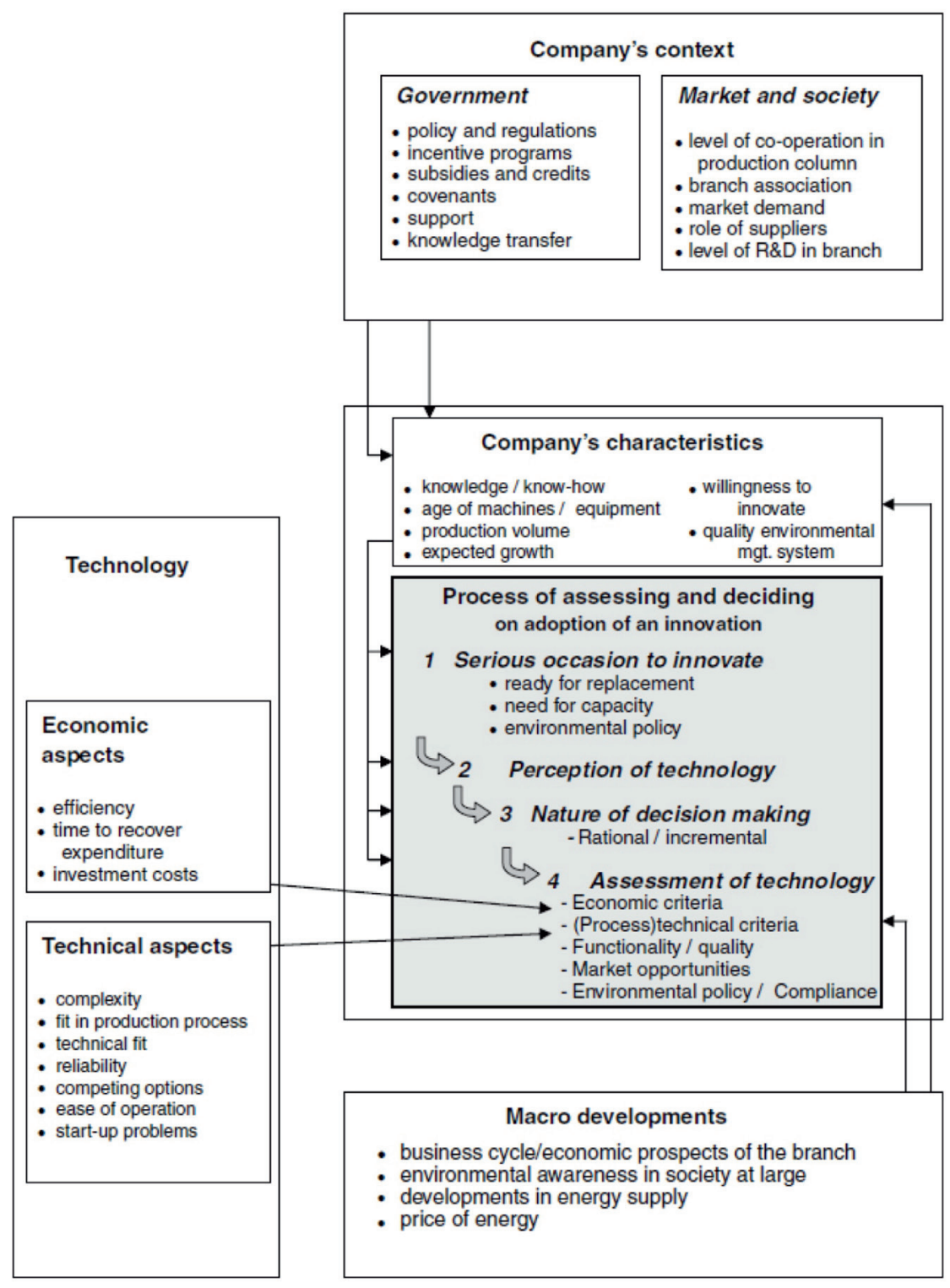

Figure 5.5 Framework for the diffusion of innovations through a process of assessment internal and external to the company in the building sector (Vermeulen \& Hovens, 2006). 
other people should do, and as a consequence, individuals create a meaning based on their own personal interests and cognitive limits (Eagly \& Kulesa, 1997).

Looking at each construction project as a network where individuals join together, actors behave in the project coherently to the common assumption and paradigm within that community (Atkinson et al., 2000). As such, networks can be thought as composed of sub-cultures in which practitioners have their own orientations and influence their understanding. Consequently, the organisation of a network of firms interested and involved in the sustainable building is a social practice engaged of a set of activities that are situated in a specific context and are influenced by a specific history. Within this context, individuals are embedded in patterns of social relationships in which values and social norms play a prime role. The history and context influence these individual's identities, their roles, responsibilities and behaviour (Gann \& Salter, 2000; Gluch, 2005).

Lockwood (2006), describing the sustainability transition of the construction sector, indicated ten drivers for the success. Among these, the most important were the coordinate management of the process of adoption of innovation and the holistic vision of the sustainable project.

The management of the adoption of green innovations is particularly difficult because construction processes are not repetitive, every project is site-adapted, and stakeholders are always project-dependent. This unrepeatable combination is typical of building processes, and makes the management of sustainable innovations in buildings difficult.

Another model for the study of sustainable innovations in construction processes has recently been proposed by Bossink (2011). He found that a sustainable innovation can be realised and managed on the level of individuals in a team, on the level of co-innovative teams in and between organisations, and on the level of business environmental forces. According to Bossink (2011), a sustainable innovation originates when these levels are synthesised together. In Figure 5.6, the model of sustainable innovation management is represented. Sustainable innovations need individuals who interact in teams: different figures are necessary for the innovation, as leaders, champions and all the other members of the team. The leadership is needed to direct a team towards an innovation. In particular, the leader has to act according to one of possible different leadership styles: he can be charismatic, instrumental, strategic or innovative. In the model of Bossink (2011), leadership is not sufficient, and the presence of an innovation champion is necessary. Champions are the creative sources of innovation. They can work in different ways, promoting, inventing and gatekeeping innovations. Leaderships and championships need to support each other. Moreover, management of the whole team is necessary to coordinate and control the sustainable innovation process. For this, systems thinking, realistic creativity, innovation foci and process linking can be used. The simultaneous 
application of some of these approaches successful supports the adoption of green innovation.

At a higher level than teams, there are the organisations. These are composed of several teams. Finally, the building sector is composed of several organisations. Cooperation and co-innovation in and between these organisations contribute to support sustainable innovations. The p-arrows between the team-circles in Figure 5.6 visualise cooperative projects between teams inside an organisation as well as between different organisations. Bossink (2011) showed that management principles that can be used to coordinate multi-teams and stimulate sustainable innovations are design-driven, planning-oriented systematic, targeted, and positioning management.

Business environmental forces can have a stimulating effect on various organisations to contribute adopting sustainable innovations. The main of these forces are sustainable innovations drivers, national policies for sustainable innovations and international issues about sustainability. These forces contribute to sustainable innovations by acting at all levels of multi-team organisations. In

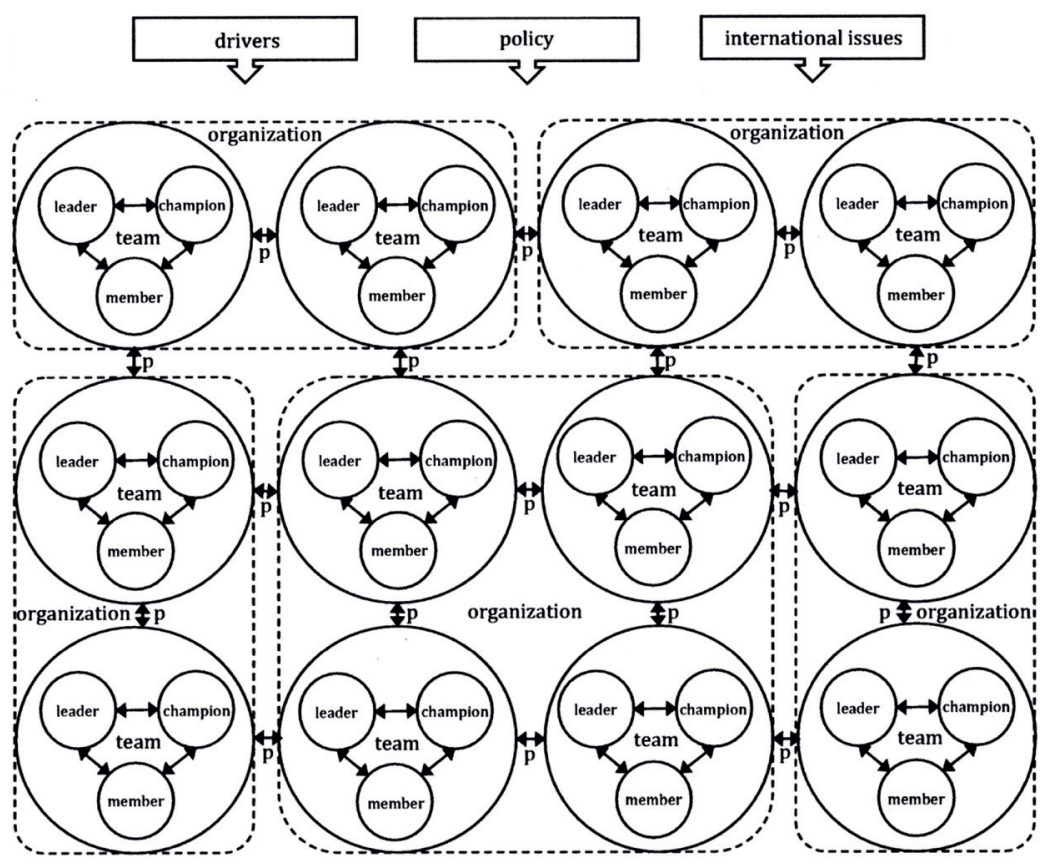

Figure 5.6 Integrated model of management of sustainable innovation considering external drivers and interactions between and within organisations (Bossink, 2011). 
fact, they exert on leaders, champions, members of teams, teams and, in and between several public and private organisations. Finally, according to Bossink (2011), sustainable innovation drivers have generally a business nature. The main of these are stakeholder pressure, technological capabilities and knowledge transfer. Obviously, actions simultaneously based on more innovation drivers contribute to the effectiveness of sustainable innovation management.

\subsection{Conclusions}

The chapter has briefly reviewed some concepts related to the classification of innovations. The concept of architecture has been discussed, with particular focus on architectural innovations. Looking at examples found in literature, some aspects of architectural innovations, as network innovations, early phase design and product modularity have been analysed. Innovation management has been discussed looking at the effects of different kinds of innovations. In particular, this analysis has been done for sustainable innovations in the building sector. This has shown the importance of stakeholders in the process of adoption, and the importance of inter-firm organisation in networks. The following chapters will investigate these influencing aspects for the management of green innovations in residential buildings. 